\title{
Students' collaboration in technology-enhanced reciprocal peer tutoring as an approach towards learning mathematics
}

\author{
Riitta Maarit Oikarinen ${ }^{1}$ D . Juho Kaleva Oikarinen ${ }^{2} \cdot$ Sari Havu-Nuutinen $^{1}$. \\ Susanna Pöntinen ${ }^{1}$
}

Received: 14 August 2021 / Accepted: 2 November 2021 / Published online: 14 February 2022

(c) The Author(s) 2022, corrected publication 2022

\begin{abstract}
Technology-enhanced Reciprocal Peer Tutoring (RPT) was carried out with Finnish, nine to ten year-old primary school students $(\mathrm{N}=40)$. The RPT as a method of paired mathematics placed specific emphasis on electrical mathematical writing and drawing. Little is known about the important area of implementing digital mathematical skills at the primary level. The contribution of this study is to address the research gap in implementing Technological Pedagogical Content Knowledge (TPACK) into primary school students' digital mathematics learning. Data was collected from one primary school mathematics lessons by videotaping student's peer collaboration. In this empirical educational study, the data was analysed qualitatively with content analysis and quantified based on the Contact Summary Sheet (CSS)-instrument and TPACK -framework. This work sheds a light on how students' collaboration such as instruction, thinking aloud, feedback, support and new ideas during their peer tutoring arouse students' mathematical attainment and technological discourse. The results indicate that all dimensions of TPACK emerged during primary school students Technologyenhanced RPT. Data reveals that there was a high degree of PK in all videotaped episodes. More research on RPT with an empirical electrical mathematical focus is needed.
\end{abstract}

Keywords Collaborative Learning (CL) $\cdot$ Peer learning digital skills $\cdot$ Reciprocal Peer Tutoring (RPT) · Technological Pedagogical Content Knowledge (TPACK)

Riitta Maarit Oikarinen

maarito@uef.fi

Extended author information available on the last page of the article 


\section{Introduction}

This work aims to implement and analyse students' collaboration in technologyenhanced RPT. Traditionally, TPACK is considered to be the knowledge teachers need in effectively integrating technology in their classrooms (Herring et al., 2016). The novelty value of this study is to address the research gap in implementing TPACK into primary school students digital mathematic learning. To our knowledge, no prior work studied how TPACK can be used in studying primary school students' peer tutoring digital skills in learning mathematics. However, in this study TPACK refers to primary school students' peer tutoring processing of digital skills during a novel RPT design (VerDi -design). TPACK was used to provide a conceptual theoretical framework to identify the relationship between technology and pedagogy in an actual educational situation. A novel reciprocal peer-tutoring design was inspired by peer-to-peer interaction and developed with Finnish schoolteachers. There is increased emphasis on collaboration in data-used settings and students' interaction in peer tutoring is seen as a useful approach to facilitate student's abilities to help each other (Walker et al., 2011).

When learning mathematics, to understand and interpret the nature of collaboration in technology-enhanced RPT, students' discourse has to be monitored, understood and characterised (Soller, 2001). Learning together takes place largely through teaching each other, expressing questions, pursuing lines of inquiry, seeing how others are learning and not barely reacting in isolation to posted materials (Stahl et al., 2006). Effective collaboration with peers involves students being encouraged to articulate their reasoning, explain and justify their opinions, ask questions, and to elaborate and reflect upon their knowledge. Peer tutoring has proved in itself to be a successful and powerful learning method, nevertheless these benefits can be achieved only in active and well-functioning learning dyads (Hmelo-Silver \& Barrows, 2008). There is a substantial amount of literature documenting the importance of successful educational experiences in students' early academic life (Fakomogbon \& Bolaji, 2017; Fantuzzo et al., 1992).

In this study, the externalisation of individual mental representations such as instruction, thinking aloud, feedback, support, and the arousal of new ideas, reflects the nature of students' collaborative peer tutoring. It seems, that students' active learning via a think-aloud strategy, can promote young students' persistent learning gains and strengthen their engagement when performing cognitively demanding tasks (Ramachandran et al., 2018). Students' externalisation of individual mental representations is based on collaborative conversational acts (Oikarinen et al., 2014; Veerman \& Veldhuis-Diermanse, 2001).

The use of RPT as an important aspect in improving education, can also be utilised in learning digital skills (Kwakman, 2003). Students' active role in learning and their earlier knowledge and experiences in peer tutoring, can facilitate learning by providing both tutor and tutee roles that can engage various cognitive and metacognitive activities. (Fantuzzo et al., 1992; Ginsburg-Block et al., 2006)). In learning digital skills, peer tutoring either between peers or with a more able peer, can be motivating through sharing cognitive processes of collaboration. Student 
interaction with computers when studying in pairs, has demonstrated positive learning effects such as improving the quality of mathematical conception (Yang et al., 2016). Previous studies have also indicated that peer tutoring potentially increases students' mathematical communication (Walker et al., 2009).

The rapid integration of information and communication technology (ICT) makes it imperative to acquire digital skills needed in the new social and technological environments (van Laar et al., 2017). These skills are often referred to as $21^{\text {st }}$ century skills containing for example: collaboration, communication, digital literacy, citizenship, problem solving, critical thinking, creativity and productivity (Voogt \& Roblin, 2012). Both $21^{\text {st }}$ century skills as well as digital skills are seen to be of crucial importance but there is no sufficient definition as to how they are to be combined (van Laar et al., 2017). Van Laar et al. (2017) considered $21^{\text {st }}$ century digital skills to be described following way. First, the mastery of ICT applications to solve cognitive tasks at work. Second, skills that are not technology-driven as they do not refer to the use of any particular software programme. Third, skills that support higher-order thinking processes. Fourth, skills related to cognitive processes favouring employees' continuous learning. In this study, digital skills refer to the mastery of ICT applications to solve cognitive tasks, skills that support higher-order thinking processes, and skills related to cognitive processes favouring students' continuous learning (van Laar et al., 2017).

Little is known about the important area of implementing digital mathematical skills at the primary level. Thus, it is vital to advance understanding of how to foster students' mathematical communication ability. Students can develop mathematical communication by simultaneously training their various mathematical representations and oral expressions. This enables concrete explanations of their understanding of mathematical ideas and strategies and promotes the sharing of work with one another (Dacey \& Eston, 2002). Students' interaction with a reciprocal, adaptive peer agent supports vocabulary learning, creates a socially rich interaction experience that in turn builds a sense of camaraderie (Chen et al., 2020). In addition, RPT encourages tutors' and tutees' emotional and relational engagement through facial expressions and non-verbal cues (ibid. 2020). This study depicts the nature of students' collaboration in technology-enhanced RPT through the use of $21^{\text {st }}$ century collaboration skills and the frame of TPACK. Effectively integrating technology into primary education is an increasingly important focus of study.

The field of TPACK developed by Mishra and Koehler (2008) is one of increasing international interest. Traditionally it delineates the knowledge teachers need in effectively integrating technology in their classrooms (Herring et al., 2016). The introduction of the TPACK framework has served to integrate many lines of research spanning multiple content areas to include several school subjects. TPACK studies have identified the relationship between technology and pedagogy in various educational situations, both in collaboration, student engagement and flexibility in learning (Lye, 2013). There have been studies in which students evaluate teachers' TPACK, but as far as we know TPACK has not been used as an analytical frame in students' videotaped reciprocal tutoring sessions. In this study TPACK refers to the peer tutoring process of the primary school students. What is not yet clear is which TPACK dimensions emerge during primary school students' mathematics lessons, 
as previous studies regarding primary school students' RPT have not focused on TPACK.

Our work makes the following contributions. First, this study examines the nature of students' RPT, using the technology-enhanced approach in learning mathematics at primary level. Second, very few studies have been conducted measuring students' TPACK. This study was conducted to fill the gap and our work is the first experiment to our knowledge that studies which dimensions of TPACK emerge during primary school students' peer tutoring in learning mathematics. The study provides analysis as to how a new pedagogical approach can support students' RPT and TPACK.

Questions under research are:

1. As a novel pedagogical approach, how does a RPT design support students' peer tutoring digital skills in learning mathematics?

1.1 What is the nature of students' collaborative peer tutoring digital skills in learning mathematics?

1.2 Which dimensions of TPACK emerge during peer tutoring in learning mathematics?

The paper is organised as follows. The next section provides theoretical review as a brief overview of previous studies. Research design and context is presented in section 4. Results are presented in section 5 and section 6 provides the discussion about the collected results. The paper ends with conclusions in section 7 .

\section{Theoretical review}

\subsection{Collaborative peer learning, $21^{\text {st }}$ century collaboration skills and RPT}

Collaborative Learning (CL) strategies which involve students working together to achieve academic objectives, have been identified to be promising classroom -based techniques (Teasley et al., 2008; Thurston et al., 2020). CL as a pedagogy, can be seen as an all-embracing term for various educational approaches which involve students' joint intellectual effort and facilitate learning (Fakomogbon \& Bolaji, 2017). In CL, students work in groups of two or more and mutually search for meanings, solutions, understanding or to create a product (Stahl et al., 2006).

Here, students' collaborations are examined through peer tutoring digital skills in learning mathematics. The literature presented in this study will encompass itself to reported research where the use of RPT, as an important aspect in improving education, can also be utilised in learning digital skills. An essential part of the CL process is the students' discourse during collaboration (Stahl et al., 2006). Recent trends in mathematics education are moving towards implementing innovative teaching and learning methods, such as those involving peer learning and 
collaboration (Germain-McCarthy, 2013). Teachers should comprehend pupils' cognitive and non-cognitive learning outcomes as data which holds great potential for developing and improving performance in mathematics education (Jimerson, 2014). One mode of collaborative peer learning is peer tutoring, which has been demonstrated as being a useful approach when facilitating student's abilities to help one another (Tsuei, 2011; Walker et al., 2011). According to Thurston et al. (2020) the peer tutoring technique, as a form of paired mathematics, significantly increased student mathematics attainment.

Peer tutoring is a pedagogical approach that shows great promise in meeting the complex academic and social demands required of $21^{\text {st }}$ century skills. Categorization of the key $21^{\text {st }}$ century skills include the promise of $21^{\text {st }}$ century learning (Binkley et al., 2012). (Fig. 1) ways of working; tools for working; ways of thinking; and living in the world. The main focus is on the transformation from traditional learning through the use of digital technologies, in order to mobilize skills that are necessary in the emerging digital environment (van Laar et al., 2017). Here, the categorization of the key $21^{\text {st }}$ century skills form one dimension for considering students' collaborative peer-tutoring.

In learning mathematics, students' collaboration through instruction, thinking aloud, feedback, support, new ideas, all are central to understanding the nature of students' collaborative peer tutoring digital skills. Students' oral expressions and various mathematical, technological representations, provide an important opportunity for advancing the understanding of primary school students' communication ability in RPT. Drawing upon two stands of research, this study attempts to depict the nature of students' collaboration in technology-enhanced RPT by using both $21^{\text {st }}$ century collaboration skills and TPACK as a frame.

The importance of the idea of knowledge acquisition as a social activity and its premise in constructivist approaches to learning, have been demonstrated in studies on peer tutoring (De Lisi \& Golbeck, 1999; Tsuei, 2012). Peer tutoring is reported to have beneficial effects on learning, and it is widely used in schools (Ginsburg-Block

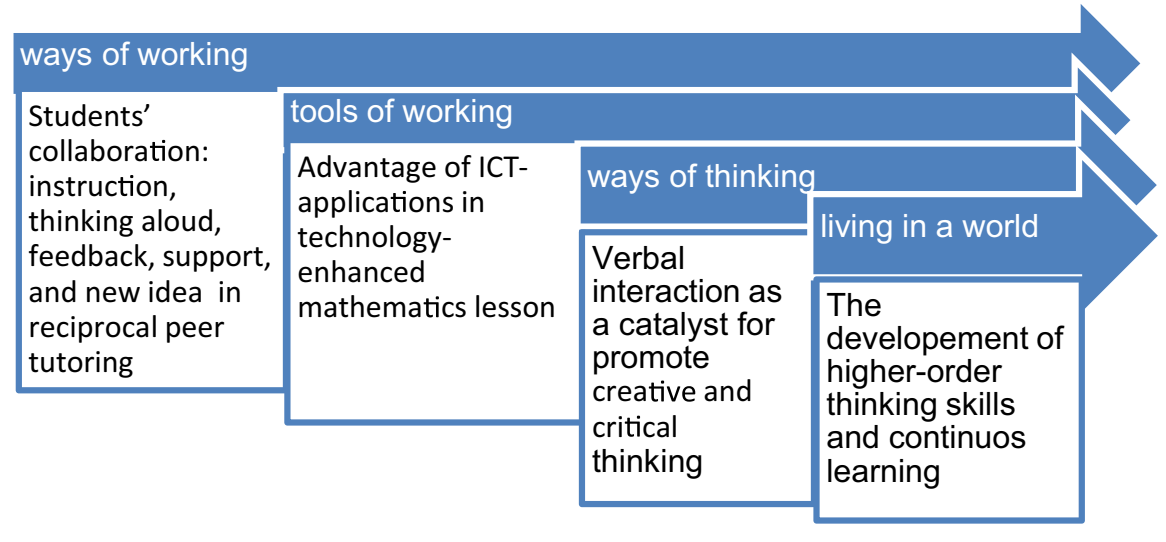

Fig. 1 Categorization of the key $21^{\text {st }}$ century skills, utilised in data analyses of students' collaborative peer-tutoring, (based on Binkley et al., 2012) 
et al., 2006). A characteristic of peer tutoring is to take a role as tutor or tutee focusing on the importance of curriculum content and a clear procedure for interaction (Topping, 2005). Pedagogical agent-role designs have been shown to promote student learning (Chen et al., 2020).

Central to peer tutoring is a type of cooperative learning, where students take proactive roles in thinking, questioning, and sharing knowledge (Clarkson et al., 2002). Benware and Deci (1984) described peer tutoring as providing an alternative teaching and learning approach; students acting as tutors and tutees increase their achievement through participation in peer tutoring. In the light of this observation, students acting as tutors benefit most from the process making greater contentspecific gains than student tutees. As a consequence, Pigott et al. (1986) developed RPT, an instructional strategy to promote mutual tutoring. RPT is also a type of cooperative learning that requires students to accomplish both tutor and tutee roles (Griffin \& Griffin, 1998; Riggio et al., 1991). Here both roles benefit from the practice in which tutors are engaged and the tutees receive assistance. Previous studies have indicated positive effects of RPT in mathematics; for example, in the training of students' mathematical expression and in the integration of prior knowledge into new knowledge (Yang et al., 2016).

The literature review in this study was selected based on Piagetian theoretical perspectives in which peer tutoring can provide cognitive challenge and social exchanges between peers and enables effective learning (Palinscar, 1998; Tenenbaum et al., 2020). To explore the cognitive mechanisms underpinning learning through peer interaction from Piagetian view, Tenenbaum et al. (2020) describe that peer interaction facilitates learning by contrasting viewpoints creating sociocognitive conflict. If the task specifically requires children to reach consensus through interaction, clear practical implications and greater learning can be expected (Tenenbaum et al., 2020).

However, there is still a need for more detailed analysis of RPT in order to understand the knowledge primary school students used in their tutoring. Previous studies have not explored the differential outcomes of RPT for those acting as peer tutor and peer tutee in studying primary school students' peer tutoring digital skills in learning mathematics. To sum up, this study examines the nature of students' RPT, using the technology-enhanced approach in learning mathematics. The study provides analysis as to how a new pedagogical approach can support students' RPT and TPACK.

\subsection{TPACK framework}

TPACK studies have identified the relationship between technology and pedagogy in various educational situations, both in student engagement and collaboration as well as flexibility in learning (Lye, 2013). The TPACK framework has been implemented in reporting average levels of technology integration in teaching and learning processes and in general, most educators designate competency with TPACK as a core attribute essential in technology integration (Benson \& Ward, 2013; Lye, 2013). Although some lines of research have studies in which students evaluate teachers 'TPACK, no studies have been found 
which identify the relationship between technology and pedagogy in primary school students' technology-enhanced RPT. Therefore, it is necessary to provide a conceptual theoretical framework for use in an actual educational situation, in order to identify the relationship between technology and pedagogy that is based on TPACK.

The three components of the TPACK are: Content Knowledge (CK), Pedagogical Knowledge (PK) and Technological Knowledge (TK) (See Fig. 2). In this study, CK depicts tutors' grasp on the subject content; PK involves tutors' knowledge about teaching and learning; and Technological knowledge depicts the understanding of technology. Fig. 2 shows the ways in which the overlap and hierarchy of the independent domains of TK, PK and CK can be seen (Mishra \& Koehler, 2008). The TPACK framework involves a complex interaction among the three major dimensions: Content, Pedagogy and Technology.

From these three domains and their complex interaction arise three additional components: Pedagogical content knowledge, Technological content knowledge and Technological pedagogical knowledge (See Fig. 2). Pedagogical content knowledge denotes appropriate methods of teaching for the distribution of a specific content; Technological content knowledge denotes tutors' knowledge on the use of appropriate technology, in order to communicate the content material within a specific discipline; and Technological pedagogical knowledge denotes how a particular technology enhances teaching and learning. All in all, the TPACK comprises of knowledge needed to effectively integrating technology in teaching.

Fig. 2 TPACK framework (Mishra \& Koehler, 2008)

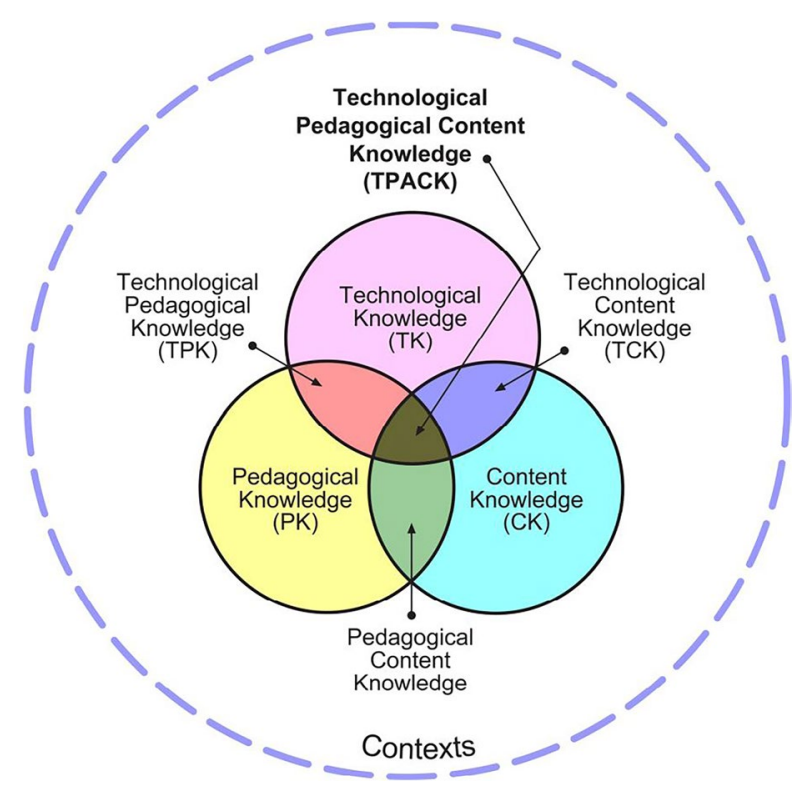




\section{Research design and context}

This case study with its design-based research (DBR) features as well as collaboration among researchers and practitioners in real-world settings, aims to improve educational practices (Wang \& Hannafin, 2005). DBR, being situated in a real educational context, is fast becoming a key instrument in seeking and increasing the impact, transfer and translation of educational research into improved practice (Anderson \& Shattuck, 2012). To obtain multidisciplinary and comprehensive results on the students' peer tutoring, both qualitative and quantitative methods have been used and combined. Qualitative methods focus on videotaped material in the real school context, as well as the researcher's notes.

The study is part of a peer tutoring design project 'VerDi -design' that aims to develop peer tutoring in primary education. VerDi is an abbreviation of the Finnish words for peer tutoring (vertaistutorointi) and digital skills (digitaidot). 'VerDi -design' was created at the Pyörö school in the Eastern part of Finland. The school students use peer tutoring digital skills in order to enhance their TPACK, and the mathematics content follows that stated in the National Curriculum.

According to the category Ways of Working from the $21^{\text {st }}$ century skills, the students' communication, collaboration and problem solving are included in the VerDi- design lessons on RPT. Fourth grade students tutor the third grade on how to use technology in learning mathematics. Tools for Work offers the capability to take advantage of ICT- applications in a technology-enhanced mathematics lesson. Here digital skills refer to electrical mathematical writing and drawing, using the ICT applications GeoGebra, Abit- editor and L'Math- editor.

Ways of Thinking is built on the idea of verbal interaction as a catalyst for promoting creative and critical thinking, while Living in the World involves the development of higher-order thinking skills and continuous learning. VerDi -design takes into consideration $21^{\text {st }}$ century skills such as collaborating, problem solving, creative and innovative thinking as well as the ability to take advantage of ICT- applications.

The local VerDi -design we used in this study proceeded in the following order: First, altogether the $6^{\text {th }}$ grade teachers studied a certain ICT -application such as GeoGebra. This way, digital skills were reciprocally absorbed downwards. The process continued onwards from the sixth to the third grade. This study examines the $4^{\text {th }}$ and $3^{\text {rd }}$ grade-students $(n=40)$ working together during the VerDi -lessons.

Second, one of these teachers taught the proposed topic to her own class instructing students to be prepared to peer teach the current topic to younger $5^{\text {th }}$ grade students. In the beginning of the VerDi-lesson, $5^{\text {th }}$ grade students were instructed to be prepared to peer teach the current topic to younger $4^{\text {th }}$ grade students. This way, digital skills were reciprocally absorbed downwards. The process continued onwards from the sixth to the third grade. This study examines the 4th and 3rd grade-students $(n=40)$ working together during the VerDi -lessons.

The objective of the VerDi lessons is to sustain an atmosphere which is open for discussion and enables visibility of the students' thinking. Cross-age grouping is an opportunity for older students to recognise how much progress they have 
made, comparing their knowledge level with younger students (Tytler, 2000). The goal of RPT is for both tutor and tutee to develop a full understanding of domain concepts, just as in other forms of CL (Walker et al., 2009). VerDi -design aims to encompass $21^{\text {st }}$ century skills and the four-core skill areas are highlighted in the students' peer tutoring (see Fig. 1).

\subsection{Participants}

The study was carried out in primary school in the Eastern part of Finland. Participating primary school students $(\mathrm{N}=40)$ studied in $3^{\text {rd }}, 4^{\text {th }}$ grades $(9-11$-year-olds). Written consent from the parents was requested before students' participation in the study; participation was voluntary, students were also asked to give their consent. All those involved were fully informed of the purpose of the design and were also notified that at any time they could withdraw from the research, no questions asked. Four students did not get consent from their parents for the collection of video material. The students' discourse was coded anonymously.

Students were paired at random in different-age dyads. Over the 5-month period, the schedule for the VerDi -groups was implemented on a weekly basis. During the school year, teachers from the $4^{\text {th }}$ and $3^{\text {rd }}$ classes met regularly to discuss the topic of the VerDi -lesson. Together they chose the mathematic content and the implementation of ICT. Teachers are collectively responsible for students' ICT learning. Students both in the roles of tutors and tutored, come from different ages and grades of study. In VerDi -design, cross-age help is considered to be an effective method in promoting cognitive gains. The speed of the process is naturally dependent on the amount of time and ICT used in the procedure.

\subsection{Procedure}

Data for this study was collected over the years 2019 and 2020. The primary data was gathered from the videotaped material. Thirteen videotaped recordings ( $5 \mathrm{~h}, 40$ min) were made of the VerDi-lessons. VerDi -lessons were implemented according to the Finnish National Curriculum for Basic Education (FNBE, 2015) and carried out in an authentic school context. Mathematical study content was selected according to the curriculum, but ICT-applications were new to the students and also partly for the teachers. Selected episodes concerned File management, Microsoft 365, GeoGebra, L'Math / Abit Editor and Division in mathematics. These video recordings were collected between December 2019 and March 2020. Thirteen videotaped recordings have been quantified by the CSS -instrument in order to depict the nature of students' RPT and also to examine which dimensions of TPACK emerge during VerDi -design lessons.

Variety of data collection techniques offer a much better opportunity to present the breadth and complexity of the data while not forgetting consensus in synthetically using numbers, text, visual and sensory data (Gorard, 2010). Data was systematically collected throughout the VerDi -design and it includes the researchers' field notes, photos of classroom events and videotaped VerDi -lessons. Field notes 
comprise of the $3^{\text {rd }}$ and $4^{\text {th }}$ grade mathematics teachers' diary used previously in the planning sessions as well as observations made during VerDi-lessons. The first author, the $4^{\text {th }}$ grade students,' class teacher, was responsible for monitoring and videotaping technology-enhanced VerDi -lessons.

This study takes into consideration ethical issues relating to the safe use of the Internet and digital devices. In classroom demonstrations, the teacher organized routines and activities that helped the students understand and cope with digital media. The purpose was to prevent students from accessing inappropriate digital content or misuse applications. Students' personal privacy was guaranteed through the creation of individual accounts in Microsoft 365 which were managed at the school level, when using devices and Online applications.

\subsection{Data analysis}

Thirteen videotaped recordings were transcribed and analysed through a method in which coding schemes were used to understand textual data (Mayring, 2004; Weber, 1990). In this study, the qualitative videotaped data was analysed by content analysis (ibid.). This was organized by using open coding to reduce the material in such a way that the essential contents were preserved (ibid.). After the videotaped data was transcribed into text, the text was broken down into paragraphs, according to the nature of the students' collaborative peer tutoring and TPACK. Each paragraph was coded using the prior categories established in the coding protocol. The coding used categories on collaboration from the $21^{\text {st }}$ Century Skills (see Fig.1).

The verbal data on students' utterances (Chi, 1997) were first classified into six categories; these were: thinking aloud, question, instruction, support, feedback and new idea. These utterances were then classified into three categories of CK, PK and TK. The dimensions of TPACK emerge in students' PK, CK and TK utterances. PK categorises comments about processes or methods of RPT; CK categorises comments about subject matter. TK categorises comments about various technologies and their features. If both CK and PK overlap, the utterance is categorised as PCK. The purpose of the presented categorisation of the analysis was to give visibility to the nature of students' collaborative peer tutoring and the dimensions of TPACK in students' discourse. Each category was analysed with respect to the nature and frequency of their utterances.

The CSS -instrument took combinations of PCK, TPK, TCK and TPACK into consideration. The data gathered according to both the nature of collaboration analyses and TPACK, was brought together to reveal a complete picture. The Pearson's correlation between technological discourse (TPACK, TCK, TPK and TK) and instructions, was examined and interpreted. Analysis is built on the idea of verbal interaction as a catalyst for finding regularity in the data. The coding scheme for tutor and tutee dialogue is presented in Table 1.

The CSS- instrument (Oikarinen et al., 2014) is a tool for analysing the nature and quantity of students' utterances while they are peer tutoring digital skills during VerDi- lessons (See Appendix Table 7). Chronological representations of discourse 


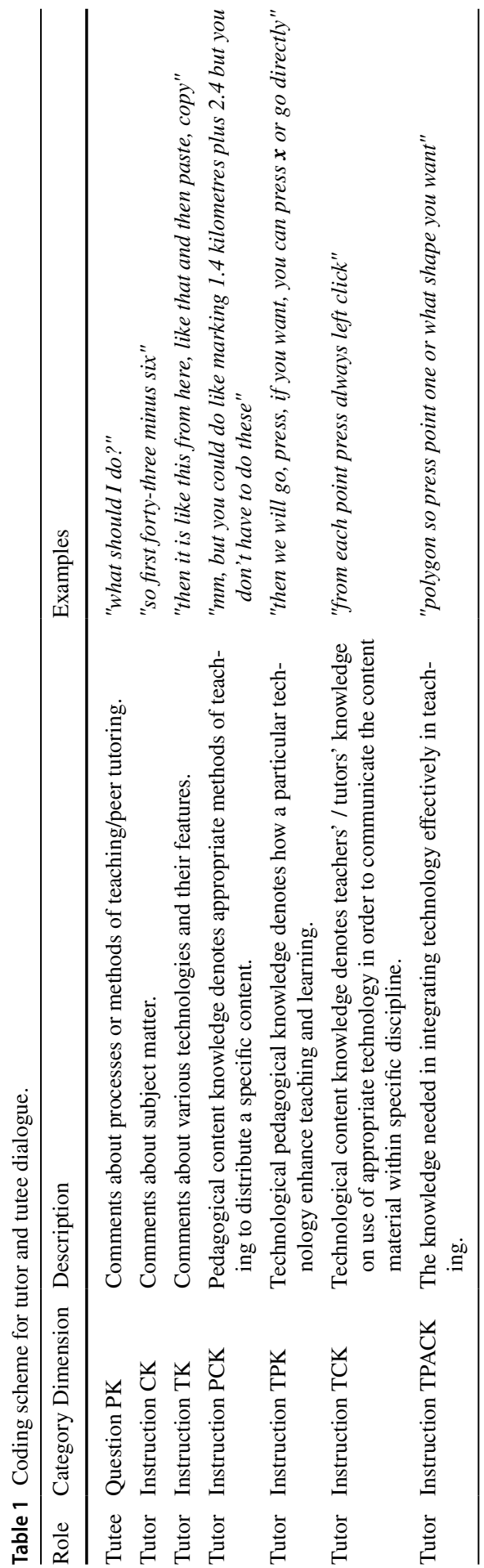


featured in the CSS-instrument, illustrates the students' collaborative peer tutoring digital skills. Peer tutoring was analysed in the mathematics learning context when students worked together with Division, L'Math, Abit-editor, Microsoft 365, File Management and GeoGebra. These ICT- applications were chosen on the basis of their future necessity at secondary level. In the Contact Summary Sheet, students' collaboration and TPACK has been coded by two independent coders.

Firstly, the videotaped discourse was transcribed ad verbatim. After transcribing the videotaped data, using the CSS-instrument, researcher (A) and researcher (B) both independently evaluated the nature and quantity of the transcribed discourse. This was followed by researchers A and B discussing the points upon which they were agreed and finally, there was discussion over the coding upon which they had differing opinions; this was essential to assure validity in the rest of the coding. The inter-rater agreement value, Cohen's Kappa $\kappa=.95$, indicates a high concurrence.

\section{Results}

This study aims to analyse how VerDi-design supported students' peer tutoring with regards to digital skills in learning mathematics. Firstly, we depicted the nature of the students' RPT and secondly, we described which dimensions of TPACK emerge during this process.

\subsection{The nature of students' RPT}

It seemed that students' collaboration had been very active in the area of peer tutoring digital skills. The nature of students' RPT was deciphered through the categories of; thinking aloud, question, instruction, support, feedback and new ideas. To some extent all the dimensions of students' collaborative discourse occurred in the videos. Results showed that most instruction occurred during the students' discourse throughout RPT. The second most noticeable part of students' utterances in RPT was thinking aloud and the third-largest category was question. The nature of students' collaborative peer tutoring in mathematics is presented in Table 2, summarising the students' utterances in the nature of RPT categorisation.

The three most frequently occurring categories were instruction, thinking aloud and question. Instruction emerged mostly and especially when peer tutoring took place with Microsoft 365, file management and GeoGebra applications. Tutor students directly, step by step instructed the tutee what needed to be done.

Students' utterances in the nature of RPT categorisation contained the most instruction. Students' utterances that were categorized under instruction refer to the teaching of a particular skill or subject advice, and with clear, firm instructions, giving information on how to do or use something. In peer tutoring episodes 3332 , 3341 and 3342, instructional utterances were used the most.

Context: Tutor instructed tutee to create a new folder in the Microsoft 365 environment.

Tutor: "and then plus (shows from the screen)" 
Table 2 The nature of students' RPT.

\begin{tabular}{|c|c|c|c|c|c|c|c|}
\hline Episode & $\mathrm{n}^{\mathrm{a}}$ & $\begin{array}{l}\text { Thinking aloud } \\
\text { frequency }\end{array}$ & $\begin{array}{l}\text { relative fre- } \\
\text { quency }\end{array}$ & $\begin{array}{l}\text { Question } \\
\text { frequency }\end{array}$ & $\begin{array}{l}\text { relative fre- } \\
\text { quency }\end{array}$ & $\begin{array}{l}\text { Instruction } \\
\text { frequency }\end{array}$ & $\begin{array}{l}\text { relative } \\
\text { fre- } \\
\text { quency }\end{array}$ \\
\hline 3302 & 121 & 46 & $38.02 \%$ & 20 & $16.53 \%$ & 41 & $33.88 \%$ \\
\hline 3331 & 38 & 9 & $23.68 \%$ & 14 & $36.84 \%$ & 14 & $36.84 \%$ \\
\hline 3332 & 19 & 1 & $5.26 \%$ & 2 & $10.53 \%$ & 16 & $84.21 \%$ \\
\hline 3333 & 69 & 14 & $20.29 \%$ & 16 & $23.19 \%$ & 32 & $46.38 \%$ \\
\hline 3334 & 36 & 10 & $27.78 \%$ & 3 & $8.33 \%$ & 19 & $52.78 \%$ \\
\hline 3335 & 167 & 42 & $25.15 \%$ & 27 & $16.17 \%$ & 82 & $49.10 \%$ \\
\hline 3337 & 35 & 12 & $34.29 \%$ & 9 & $25.71 \%$ & 11 & $31.43 \%$ \\
\hline 3338 & 27 & 7 & $25.93 \%$ & 7 & $25.93 \%$ & 12 & $44.44 \%$ \\
\hline 3341 & 51 & 5 & $9.80 \%$ & 3 & $5.88 \%$ & 37 & $72.55 \%$ \\
\hline 3342 & 75 & 6 & $8.00 \%$ & 12 & $16.00 \%$ & 53 & $70.67 \%$ \\
\hline Episode & $\mathrm{n}$ & $\begin{array}{l}\text { Support } \\
\text { frequency }\end{array}$ & $\begin{array}{l}\text { relative fre- } \\
\text { quency }\end{array}$ & $\begin{array}{l}\text { Feedback } \\
\text { frequency }\end{array}$ & $\begin{array}{l}\text { relative fre- } \\
\text { quency }\end{array}$ & $\begin{array}{l}\text { New Idea } \\
\text { frequency }\end{array}$ & $\begin{array}{l}\text { relative } \\
\text { fre- } \\
\text { quency }\end{array}$ \\
\hline 3302 & 121 & 11 & $9.09 \%$ & 10 & $8.26 \%$ & 3 & $2.48 \%$ \\
\hline 3331 & 38 & 1 & $2.63 \%$ & 0 & $0.00 \%$ & 0 & $0.00 \%$ \\
\hline 3332 & 19 & 2 & $10.53 \%$ & 1 & $5.26 \%$ & 0 & $0.00 \%$ \\
\hline 3333 & 69 & 4 & $5.80 \%$ & 5 & $7.25 \%$ & 1 & $1.45 \%$ \\
\hline 3334 & 36 & 3 & $8.33 \%$ & 1 & $2.78 \%$ & 0 & $0.00 \%$ \\
\hline 3335 & 167 & 19 & $11.38 \%$ & 9 & $5.39 \%$ & 1 & $0.60 \%$ \\
\hline 3337 & 35 & 2 & $5.71 \%$ & 1 & $2.86 \%$ & 0 & $0.00 \%$ \\
\hline 3338 & 27 & 1 & $3.70 \%$ & 0 & $0.00 \%$ & 0 & $0.00 \%$ \\
\hline 3341 & 51 & 5 & $9.80 \%$ & 4 & $7.84 \%$ & 0 & $0.00 \%$ \\
\hline 3342 & 75 & 4 & $5.33 \%$ & 2 & $2.67 \%$ & 0 & $0.00 \%$ \\
\hline
\end{tabular}

${ }^{a}$ Letter $\mathrm{n}$ describes the frequency of utterances in the selected episode.

Tutor: "and then write there, that's where you write your name."

Tutor: "alright, then One Drive."

Tutor: "then grade 3"

Tutor: "then open from the text so that you can get then"

Tutor: "mm math"

Tutor: "Abit editor"

Tutor: "actually, here is your old one, go forward still from that arrow, like that"

Tutor: "like that and from there new and Word document"

Tutor: "first chance to be Abit editor 2"

This episode demonstrated the tutor's verbal instruction and depicted how the instructions given to the tutee were accurate and well-organized. The tutor's verbal instruction contained a large number of technological terms, such as "One 
Drive, Abit editor, arrow, Word document'. The nature of this instructional collaboration affirmed the tutors' active pedagogical role in peer tutoring digital skills during the VerDi -lesson.

The second-largest nature category in RPT was thinking aloud. The students verbally expressed when they counted and also what they were thinking. The thinking aloud category emerged mostly in episodes 3302, 3337 and 3334 and in contexts of Division and L'Math/Abit-editor.

Context: The tutor and tutee were thinking aloud about Division.

Tutee: "dadaa (raises his hand up)"

Tutor: "four"

Tutee: "seventy-two divided, mm (checks the division from the paper) divided, now I should calculate this"

Tutee: "six, twelve, twenty-four"

Tutee: "and thirty"

The episode demonstrated the tutees' verbal thinking aloud, depicting how by using this method, the tutee made his thinking of Divisions visible to the tutor. Also, the tutees' nonverbal encouragement cue to raise up his hands, depicted the tutees' positive response to the peer tutor.

The nature of the third-largest category in RPT was question. Students' utterances in the collaboration categorisation contained the most questions in the peer tutoring episodes 3331, 3338 and 3337. Students used most question utterances while they were studying Microsoft 365, File management, Division and L'Math/ Abit-editor.

Context: The tutee was eager to know how to create a new folder in the Microsoft 365 environment and the tutor was asking proper questions in order to proceed with the process.

Tutee: then?

Tutee: "what should I do in the folders?"

Tutee: "do I open writings? writings?"

Tutor: "do you have Abit there?"

Tutor: what are you wri ...(checks the screen and writes himself)

Once again, this episode demonstrated the tutees' and tutor's verbal questions and depicted how reciprocal questions enhanced tutoring. Students proceeded by asking and answering questions and giving and receiving explanations. The episode also showed how student's abilities to help each other occurred during RPT.

Support, feedback, and new idea utterances in collaboration were most frequent in episodes 3335 and 3302 while they were studying Division and 0365.

Context: Tutor was supporting the tutee with Division.

Tutor: "think, this is difficult, and it doesn't matter if it goes wrong."

Tutor: "we can skip this one, we can take another exercise, if this is too difficult"

Tutor \& Tutee: "(girls laugh together)" 
The tutor's positive response to the tutee included verbal and nonverbal encouragement cues, evidencing their emotional and relational engagement in RPT. Students' interaction created a socially rich interaction experience that in turn built a sense of camaraderie.

The nature of the fifth-largest category in RPT was feedback. In episode 3302 while studying Division and Microsoft 365, the tutor gave both positive and negative feedback to the tutee.

Context: The positive and negative feedback given by the tutor to the tutee while studying Division and Microsoft 365.

Tutor: "so very fast"

Tutor: "good"

Tutor: "that's enough"

Tutor: "no, don't' do that, no, no"

Tutor: "don't, don't"

Throughout all the episodes, feedback between the tutor and tutee occurred as a positive or negative response. Feedback and support from peers were important dimensions of students' reciprocal collaborative discourse in developing non-threatening evaluation practice during VerDi -lessons. Nevertheless, in order for effective collaboration with peers, to succeed, this involved students being encouraged to articulate their reasoning.

Surprisingly few of the selected episodes included new idea utterances, even though ICT-applications (GeoGebra, L'Math and Abit-editor) were presented to the $3^{\text {rd }}$ grade students for the first time. New idea utterances in collaboration were most frequent in episode 3302 while they were studying Division and Microsoft 365.

Context: The tutee expressed new ideas during peer tutoring on Divisions.

Tutee: "aa, like that, ok (laughs)"

Tutee: "mm, it's three"

Tutee: "aa, plus, plus ten is twenty-five"

The episode demonstrated the tutees' verbal new idea utterances and depicts how, during RPT, the tutee expressed new ideas to the tutor. The social context of one-to-one instruction supported students in articulating their reasoning.

To summarize, the nature of students' collaborative peer tutoring digital skills during mathematics lessons reflected good tutoring behaviour. It seemed that students' active learning via a think-aloud strategy, promoted RPT activity during the technology-enhanced VerDi -lessons. In terms of the nature of students' RPT, to some extent all the dimensions of students' collaborative discourse were apparent, but above all, students' discourse contained instruction. Two of the most frequently occurring categories after instruction were thinking aloud and question. 


\subsection{The Dimensions of TPACK emerge during VerDi -design}

The videos revealed that to some extent, all the dimensions of TPACK emerged in the students' collaborative discourse; data revealed that while using peer tutoring, students took on tutor and tutee roles and engaged in dialogue. Students' collaborative discourse included PK, CK, TK, PCK, TCK, TPK and TPACK utterances and the results showed that students' discourse contained most frequently TPK, PK and PCK utterances. These results during VerDi-lessons, affirmed the tutors' active pedagogical role in peer tutoring digital skills. Table 3 summarises the students' utterances in the TPACK categorisation.

Data indicated that in all the episodes there was a high degree of PK which categorises comments on processes or methods of peer tutoring. Also, the magnitude of TPK and PCK seemed to be high, indicated by the fact that the dimensions of TPK in students' discourse were high when they were peer tutoring GeoGebra, Microsoft 365 or File Management. These results showed that the percentage of technological pedagogical utterances increased on certain topics. Table 4 presents the distribution of students' TPK discourse.

In episode 3332, students' utterances in the dimensions of TPACK categorisation, contained most TPK in peer tutoring. Students used most TPK while they were studying File management and Microsoft 365.

Context: The Tutor's TPK supported tutee in creating a new folder in the Microsoft 365 environment.

Tutor: "then, I'm not sure if it was control v"

Tutor: "and then we enlarge it (takes the mouse and enlarges the screenshot)"

Tutor: "and then Abit editor two, from there"

Tutor: "and then you'll sign out, just press $x$ "

The episode depicted how the tutor's TPK helped the tutee in performing the assigned task. Technological pedagogical knowledge denoted how a particular technology enhances teaching and learning.

Table 5 presents distribution of students' PCK discourse. It seemed that the dimensions of PCK in students' discourse were high when they were peer learning Division. Pedagogical content knowledge denoted appropriate methods of teaching to distribute a specific content.

Division exercises included computations appropriate for $3^{\text {rd }}$ - and $4^{\text {th }}$ - grade students such as Multiplication and Division problems requiring more advanced operations. They even developed their own strategies to solve cognitively demanding tasks.

Context: Students developed their own strategies to solve cognitively demanding tasks with Divisions.

Tutor: "48 divided by eight"

Tutee: "I can't"

Tutor: "try"

Tutor: "eight plus eight"

Tutee: "sixteen"

Tutor: "sixteen plus sixteen" 


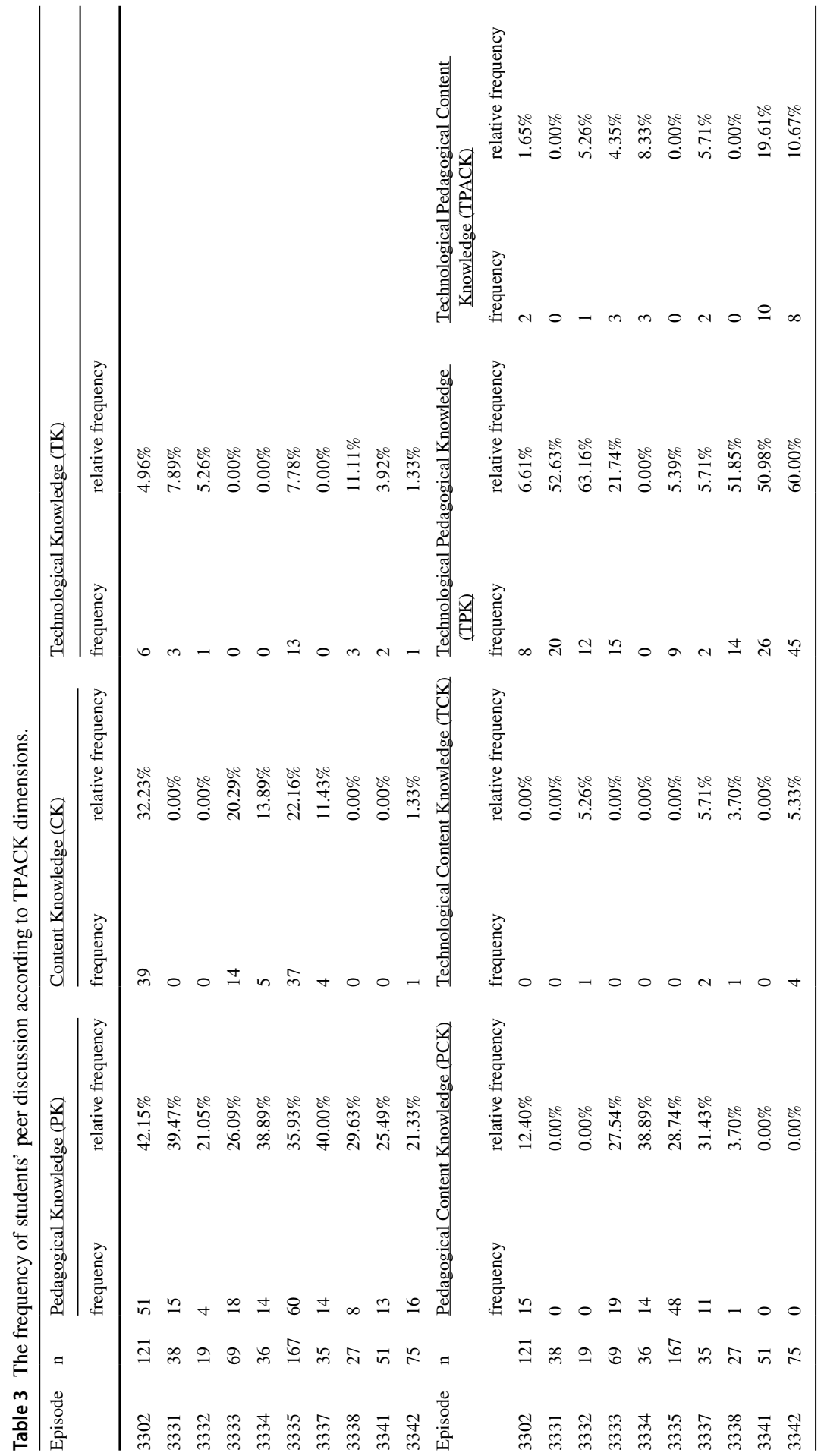




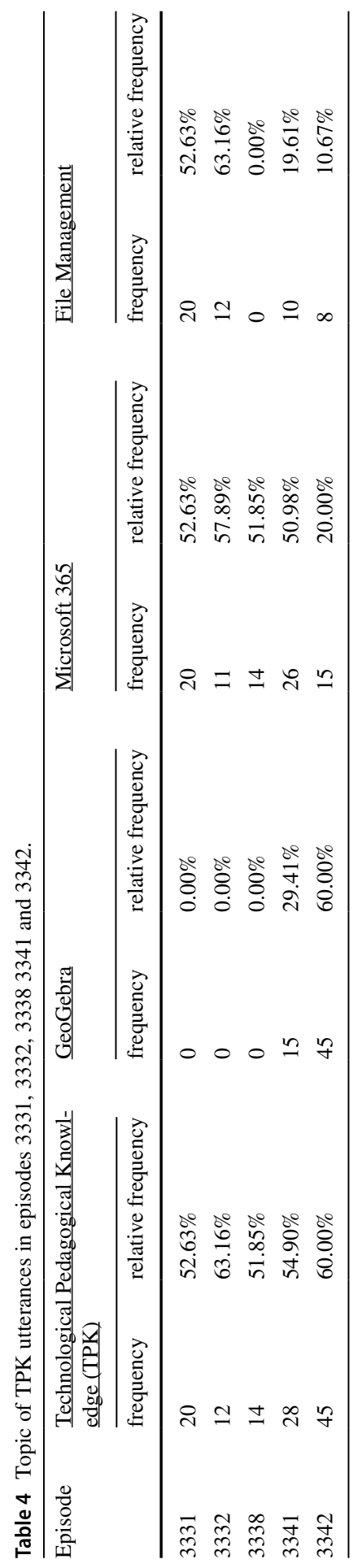




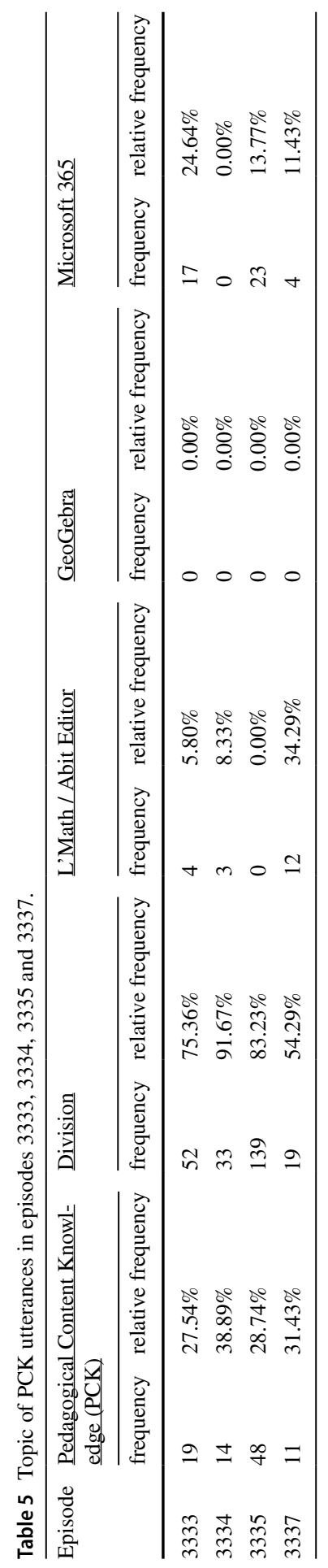




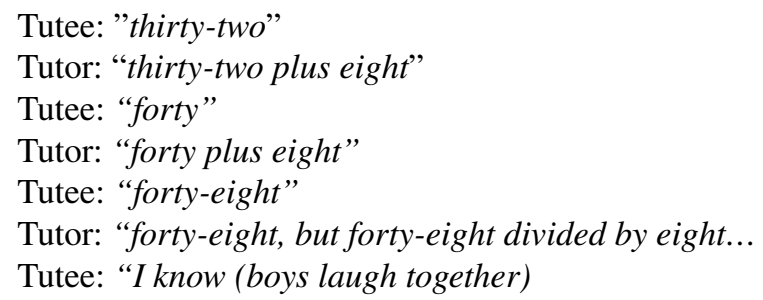

In this episode the tutor was capable of breaking down the mathematical task into smaller parts and by doing so, simplified the tutee's part without giving the correct answer right away. The episode also showed the change from the tutee's initial reluctance to calculate, into giving a positive response to the tutor's verbal and nonverbal encouragement cues.

Students' utterances in the dimensions of TPACK categorisation were most frequent in episode 3341 while they were studying GeoGebra. TPACK referred to the knowledge needed in effectively integrating technology in tutoring.

Context: Students studied geometry through the use of GeoGebra

Tutor: "first we will take these points from here"

Tutor: "let's make a new point, you can put it anywhere, point A and somewhere else point B"

Tutor: "press point $B$, move that mouse (shows with the mouse)"

Tutor: "then move the mouse to point A and now press, good"

Tutor: "press this, take from the upper corner and press the mouse all the time"

In the episode above, the tutor was capable of teaching how to draw a line between two points using GeoGebra. Through student engagement and collaboration, the tutor was capable of constructing the relationship between technology, content and pedagogy.

\subsection{Students' technological and instructional discourse in collaborative peer tutoring in mathematics}

The collaborative dialogue data collected in each episode gave us insight across collaborative conditions, into the correlation between instruction and TPACK dimensions with TK features. The magnitude of instruction in students' collaborative peer tutoring discourse was high when the magnitude of TPACK, TCK, TPK and TK were at a high level (see Tables 2 and 3). All the dimensions which had technological knowledge features (TK, TPK, TCK and TPACK) were added together as Technological discourse (Table 6). In the tutoring of digital skills, Instruction discourse was on a high level in collaborative peer tutoring.

When collaborative discourse included abundantly instructional discourse, students' technological discourse was effectively utilised in RPT. Our findings revealed that during peer tutoring digital skills, tutors' instructional discourse seemed to reinforce the technological dimensions of TPACK. The Pearson's correlation between technological discourse (TPACK, TCK, TPK and TK) and instructions was $r=.661$ $(\mathrm{N}=10)$ which indicated a moderate positive correlation $(\mathrm{p}=.03)$. These results 
Table 6 Students' technological and instructional discourse in collaborative peer tutoring in mathematics.

\begin{tabular}{lll}
\hline Episode & Technological discourse & Instruction \\
\hline 3302 & $13.22 \%$ & $33.88 \%$ \\
3331 & $60.53 \%$ & $36.84 \%$ \\
3332 & $78.95 \%$ & $84.21 \%$ \\
3333 & $26.09 \%$ & $46.38 \%$ \\
3334 & $8.33 \%$ & $52.78 \%$ \\
3335 & $13.17 \%$ & $49.10 \%$ \\
3337 & $17.14 \%$ & $31.43 \%$ \\
3338 & $66.67 \%$ & $44.44 \%$ \\
3341 & $74.51 \%$ & $72.55 \%$ \\
3342 & $77.33 \%$ & $70.67 \%$ \\
\hline
\end{tabular}

indicated that the social context of one-to-one instruction in RPT, enhanced students in TK to articulate their reasoning.

\section{Discussion}

This study explored how VerDi -design as a novel pedagogical approach, supported students' peer tutoring digital skills in learning mathematics. According to the study findings, the students' collaboration in technology-enhanced RPT was active and well-focused on the mathematical and technological communication. Along with several recent papers Tenenbaum et al. (2020) conducted a meta-analyses of 71 studies to investigate peer interaction. Their study confirmed that across different gender and age groups peer interaction was effective in promoting learning. Based on their study, children learned more when they completed a task with their peers.

The nature of students' RPT included prior categories of 21st Century Skills collaboration. Although the three most frequently occurring categories were instruction, thinking aloud and question, instruction as the most frequently occurring category affirms the tutors' active pedagogical role in peer tutoring. Instruction emerged mostly and especially when peer tutoring coincided with Microsoft 365, file management and GeoGebra applications. This indicates the tutor's strong role in dialogue. Most of the instructional utterances were initiated by the tutors; tutees played a less active role.

In the light of these observations, one important finding in our study was that all dimensions of TPACK emerged during primary school students' RPT. This study gives a brief overview how TPACK-framework underpinned the data analyses with respect to the nature and frequency of utterances. The presented categorisation made dimensions of TPACK visible in students' collaborative peer tutoring discourse. Moreover, a high degree of PK in all episodes of the VerDi -lessons, confirmed tutors' active pedagogical role in peer learning digital skills. This study demonstrated that in TK, the social context of one-to-one instruction in RPT produces a strong positive effect on students' articulation and reasoning (Thurston et al., 2020). 
Students' technological communication and mastery of ICT applications seems to support thinking processes during collaboration.

Similarly, there seems to be positive correlation between instruction and TPACK dimensions with TK features across collaborative conditions. It may indicate that there is a connection between these variables. In other words, when tutors' instructional discourse varies, the technological dimensions of TPACK varies in the same direction. One plausible reason for that is the relation between enhanced digital skills and the development of cognitive processes during RPT. Also, Tenenbaum et al. (2020) discovered that peer interaction was more effective when children were specifically instructed to reach consensus than they are not.

The explanation process during VerDi -lessons improves the learners' retention of information while benefits to the tutor stem from practising skills already acquired and being able to generalise on these existing skills. Students have to understand classmates' thinking processes in order to provide immediate learning information and disclose their thoughts to each other (Yang et al., 2016). The tutor learns by doing and teaching and can relate his own concepts to peers through instruction, whereas the tutee learns by observing, analysing and offering performance-related feedback (Thurston et al., 2009; Topping, 2005; Walker et al., 2009). These findings are similar to those in our study on VerDi -design.

As found in prior studies (Fakomogbon \& Bolaji, 2017) students' joint intellectual effort facilitates learning. In line with other previous studies (Yang et al., 2016) student interaction, when working with computers in pairs, has demonstrated positive learning effects. Furthermore, based on results, sharing and joint work combined with students' engagement in helping others, were important aspects in the development of students' digital skills (Pöntinen \& Räty-Záborszky, 2020). Previous studies have also indicated that peer tutoring potentially increases students' mathematical communication (Walker et al., 2009). Students, when finding themselves in the position of explaining or teaching concepts to one another, consider it to be an authentic, motivating context which gave their communication meaning (Fakomogbon \& Bolaji, 2017). Acknowledging the impact of technology on the learning of mathematics is an area of research that may not have been systematically pursued.

The VerDi -design faces a growing need to address students' educational, social and technical competence in modern society. VerDi -design is one example of how the 21 st century learners' competences in collaboration, student engagement and TPACK may be forthright and cost-effectively implemented in school practices. VerDi -design is not a substitute for teaching but rather an important addition to the repertoire of teaching and learning activities that may enhance the quality of education. These interventions may broaden the scope of the present study and result in improvements in peer tutoring in both technology-enhanced and face-to-face classroom settings.

Finally, along with several recent papers (Fakomogbon \& Bolaji, 2017; Tenenbaum et al., 2020; Walker et al., 2009) our results are in line with other collaborative results, that suggest that learning in collaborative conditions in RPT is an essential addition to learning individually. The underlying idea of knowledge acquisition as a social activity is crucial in technology-enhanced reciprocal peer learning during 
VerDi -lessons. In conclusion, our study provides promising results; particularly in mathematics, VerDi -design as a pedagogical approach, can significantly enhance social and technical competence for primary school students.

\section{Conclusions}

This study is the first to implement and evaluate the RPT technique, a form of paired mathematics placed specific emphasis on electrical mathematical writing and drawing. The novelty value of this study is to address the research gap in implementing TPACK into primary school students digital mathematic learning, since previous studies have not studied TPACK from this perspective in a real school context at primary level. One previously unknown value of this study was to utilise the TPACK-framework as a tool for analysis at primary level and combined with the use of ICT-applications it revealed which dimensions of TPACK emerge during RPT in learning mathematics.

In the videos we annotated, we found that children who interacted with reciprocal peer tutor showed active mathematical and technological communication. It can be suggested that cross-age RPT supported students' reflection, the exchange of mathematical ideas, and shared problem solving. An important finding in our study was that all dimensions of TPACK emerged during primary school students' RPT. Moreover, a high degree of PK in all episodes of the VerDi -lessons, confirmed tutors' active pedagogical role in peer learning digital skills. Along with several recent papers (Fakomogbon \& Bolaji, 2017; Tenenbaum et al., 2020; Walker et al., 2009) our results are in line with other collaborative results, that suggest that learning in collaborative conditions in RPT has positive impact on tutor and tutee outcomes.

The possible limitations of the current study should also be discussed. The reader should bear in mind that with a small number of participants, there are limitations in generalising the findings of this study. To validate the results of VerDi -design as being a well-functioning pedagogical approach, further research should be conducted in this area using a wider educational context in actual school settings. However, further work is required to explore whether the results of this study can be generalised to a larger population of students.

There are number of ways this study could be extended. Future studies can explore whether students' capability to use mathematics editor already at the primary level, has influence on students' mathematical prospects at the secondary level. It seems that the TPACK-framework is a utilitarian tool for analysis also with primary school students. Furthermore, if competency with TPACK is considered as a core attribute essential to technology integration, it is all-important for educators to identify the relationship between technology and pedagogy in various educational situations. We believe that the interaction affordances and supports positive emotional and relational engagement with peer and effects on learning outcomes. 


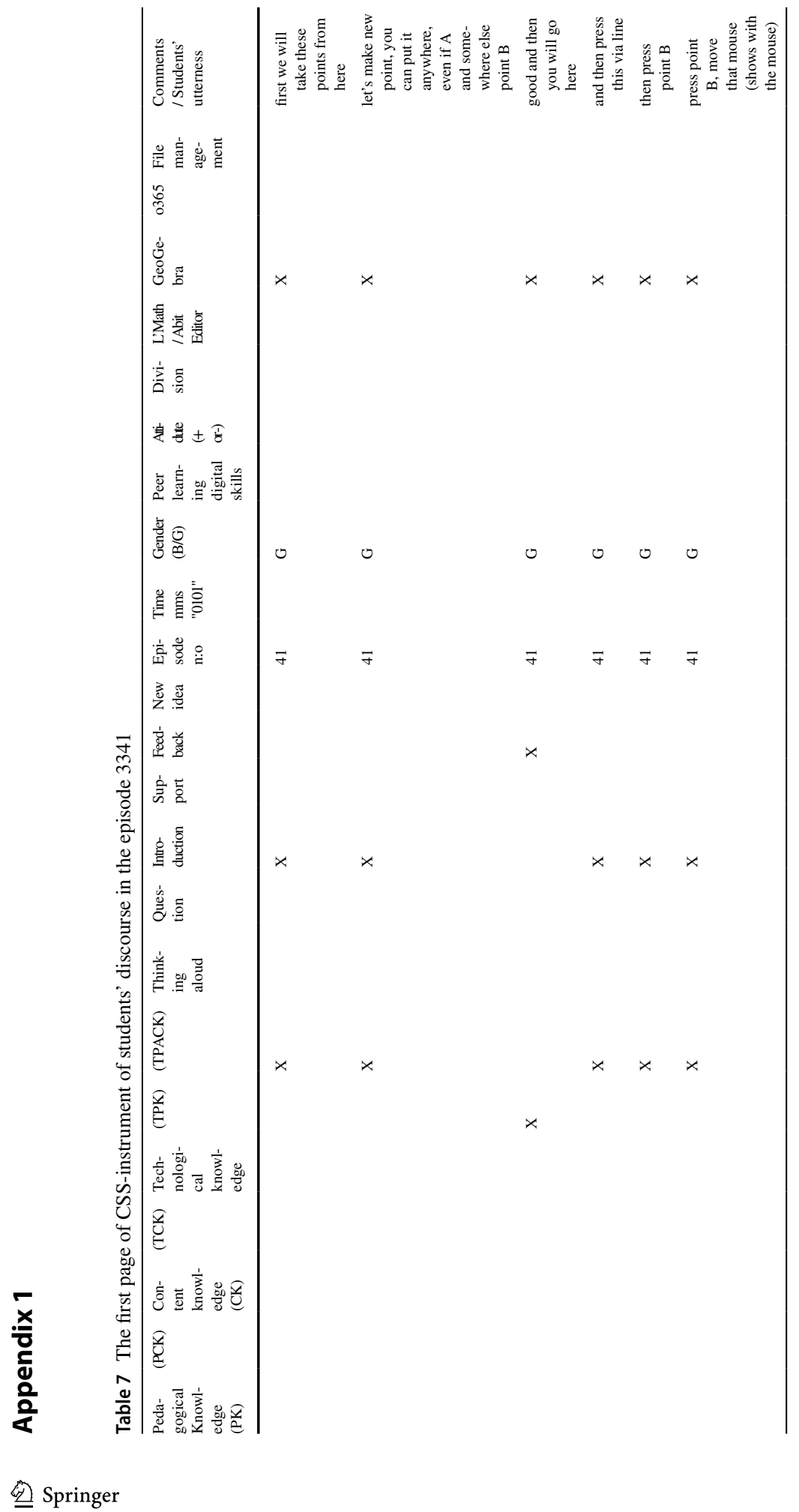




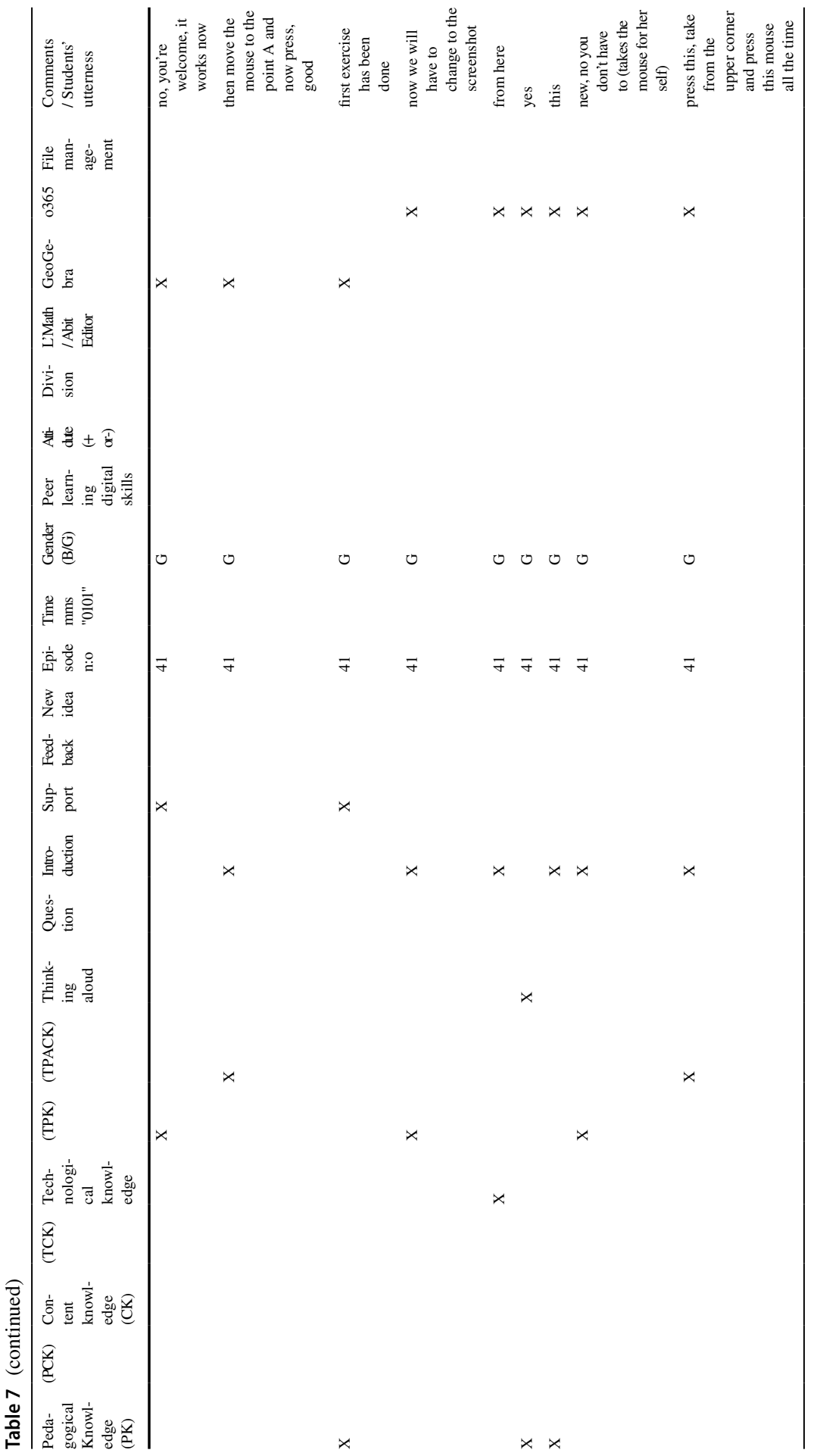




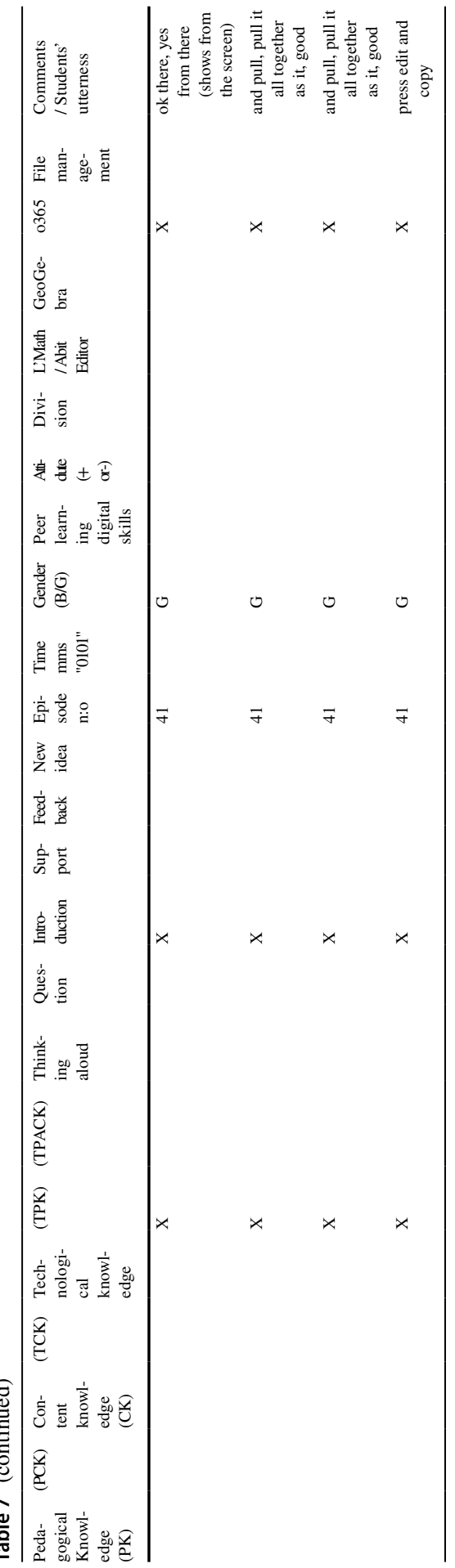


Acknowledgements This study has been supported by The Finnish Cultural Foundation.

Funding Open access funding provided by University of Eastern Finland (UEF) including Kuopio University Hospital.

\section{Declarations}

Conflicts of interest/Competing interests The authors declare that they have no conflict of interest.

Open Access This article is licensed under a Creative Commons Attribution 4.0 International License, which permits use, sharing, adaptation, distribution and reproduction in any medium or format, as long as you give appropriate credit to the original author(s) and the source, provide a link to the Creative Commons licence, and indicate if changes were made. The images or other third party material in this article are included in the article's Creative Commons licence, unless indicated otherwise in a credit line to the material. If material is not included in the article's Creative Commons licence and your intended use is not permitted by statutory regulation or exceeds the permitted use, you will need to obtain permission directly from the copyright holder. To view a copy of this licence, visit http://creativecommons.org/licen ses/by/4.0/.

\section{References}

Anderson, T., \& Shattuck, J. (2012). Design-Based Research: A Decade of Progress in Education Research? Educational Researcher, 41(1), 16-25. https://doi.org/10.3102/0013189X11428813

Benson, S. K., \& Ward, C. L. (2013). Teaching with Technology: Using TPACK to Understand Teaching Expertise in Online Higher Education. Journal of Educational Computing Research, 48(2), 153-172. https://doi.org/10.2190/EC.48.2.c

Benware, C. A., \& Deci, E. L. (1984). Quality of Learning With an Active Versus Passive Motivational Set. American Educational Research Journal, 21(4), 755-765. https://doi.org/10.3102/ 00028312021004755

Binkley, M., Erstad, O., Herman, J., Raizen, S., Ripley, M., Miller-Ricci, M., \& Rumble, M. (2012). Defining Twenty-First Century Skills. In P. Griffin, B. McGaw, \& E. Care (Eds.), Assessment and Teaching of 21st Century Skills (pp. 17-66). Springer. https://doi.org/10.1007/ 978-94-007-2324-5

Chen, H., Won Park, H., \& Breaseal, C. (2020). Teaching and learning with children: Impact of reciprocal peer learning with a social robot on children's learning and emotive engagement. Computers \& Education, 150. https://doi.org/10.1016/j.compedu.2020.103836

Chi, M. T. (1997). Quantifying Qualitative Analyses of Verbal Data: A Practical Guide. The Journal Of Thr Learning Sciences, 6(3), 271-315.

Clarkson, B., Luca, J., \& Cowan, E. (2002). Promoting Student Learning through Peer Tutoring - A Case Study. In P. Barker, \& S. Rebelsky (Ed.), Proceedings of ED-MEDIA 2002--World Conference on Educational Multimedia, Hypermedia \& Telecommunications (pp. 1176-1181). Denver: Association for the Advancement of Computing in Education (AACE).

Dacey, L., \& Eston, R. (2002). Show and tell: representing and communicating mathematical ideas in $K$-2 classrooms. Math Solutions Publications.

De Lisi, R., \& Golbeck, S. L. (1999). Implication of Piaget's theory for peer-learning. In A. M. O’Donnell \& A. King (Eds.), Cognitive perspectives on peer-learning (pp. 3-38). Lawrence Erlbaum Associates.

Fakomogbon, M. A., \& Bolaji, H. O. (2017). Effects of Collaborative Learning Styles on Performance of Students in a Ubiquitous Collaborative Mobile Learning Environment. Contemporary Educational Technology, 8(3), 268-279.

Fantuzzo, J. W., King, J. A., \& Heller, L. R. (1992). Effects of Reciprocal Peer Tutoring on Mathematics and School Adjustment: A Component Analysis. Journal of Educational Psychology, 84(3), 331-339. 
Finnish National Agency for Education. (2017, 10 16). Finnish National Agency for Education. Retrieved from The new curricula in a nutshell: http://www.oph.fi/english/curricula_and_quali fications/basic_education/curricula_2014.

FNBE. (2015, 7 20). Finnish National Board of Education. Retrieved 1 15, 2017, from Curricula and qualifications: http://www.oph.fi/english/curricula_and_qualifications.

Germain-McCarthy, Y. (2013). Bringing the NCTM Standards to Life: Exemplary Practices for Middle School. Routledge.

Ginsburg-Block, M. D., Rohrbeck, C. A., \& Fantuzzo, J. W. (2006). A Meta-Analytic Review of Social, Self-Concept, and Behavioral Outcomes of Peer-Assisted Learning. Journal of Educational Psychology, 98(4), 732-749. https://doi.org/10.1037/0022-0663.98.4.732

Gorard, S. (2010). Research design, as independent of methods. In C. Teddlie \& A. Tashakkori (Eds.), Handbook of Mixed Methods in Social \& Behavioral Research (pp. 237-252). Sage.

Griffin, M. M., \& Griffin, B. W. (1998). An investigation of the effects of reciprocal peer tutoring on achievement, self-efficacy, and test anxiety. Contemporary Educational Psychology, 23(3), 298311. https://doi.org/10.1006/ceps.1998.0971

Herring, M. C., Koehler, M. J., Mishra, P., Rosenberg, J. M., \& Teske, J. (2016). Introduction to the Second Edition of the TPACK Handbook. In M. C. Herring, M. J. Koehler, \& P. Mishra (Eds.), Technological Pedagogical Content Knowledge (TPACK) for Educators (pp. 1-8). Routledge.

Hmelo-Silver, C. E., \& Barrows, H. S. (2008). Facilitating Collaborative Knowledge Building. Cognition and Instruction, 26(1), 48-94.

Jimerson, J. B. (2014). Thinking about data: Exploring the development of mental models for "data use" among teachers and school leaders. Studies in Educational Evaluation, 42, 5-14. https://doi.org/10. 1016/j.stueduc.2013.10.010

Kwakman, K. (2003). Factors affecting teachers' participation in professional learning activities. Teaching and Teacher Education, 19, 149-170. https://doi.org/10.1016/S0742-051X(02)00101-4

Lye, L. T. (2013). Opportunities and Challenges Faced by Private Higher Education Institution Using the TPACK Model in Malaysia. Procedia - Social and Behavioral Sciences, 91, 294-305. https://doi. org/10.1016/j.sbspro.2013.08.426

Mayring, P. (2004). Qualitative Content Analysis. In U. Flick, E. von Kardoff, \& I. Steinke (Eds.), A Companion to Qualitative Research (pp. 266-269). SAGE Publicications Ltd.

Mishra, P., \& Koehler, M. J. (2008). Introducing Technological Pedagogical Content Knowledge. Research on Schools, Neighborhoods and Communities: Toward Civic Responsibility 2008 Annual Meeting Program (pp. 1-16). New York City: The American Educational Research Association.

Oikarinen, J., Järvelä, S., \& Kaasila, R. (2014). Finnish Upper Secondary Students' Collaborative Processes in Learning Statistics in a CSCL Environment. International Journal of Mathematical Education in Science and Technology, 45(3), 325-348.

Palinscar, A. S. (1998). Social constructivist perspectives on teaching and learning. Annu. Rev. Psychol., 49, 345-375.

Pigott, H. E., Fantuzzo, J. W., \& Clement, P. W. (1986). The effects of reciprocal peer tutoring and group contingencies on the academic performance of elementary school children. Journal of Applied Behavior Analysis, 19(1), 93-98. https://doi.org/10.1901/jaba.1986.19-93

Pöntinen, S., \& Räty-Záborszky, S. (2020). Pedagogical aspects to support students' evolving digital competence at school. European Early Childhood Education Research Journal, 28(2), 182-196. https://doi.org/10.1080/1350293X.2020.1735736

Ramachandran, A., Huang, C.-M., Gartland, E., \& Scassellati, B. (2018). Thinking Aloud with a Tutoring Robot to Enhance Learning. In Proceedings of 2018 ACM/IEEE International Conference on HumanRobot Interaction (HRI '18) (pp. 59-68). ACM, New York, USA. https://doi.org/10.1145/ 3171221.3171250

Riggio, R. E., Fantuzzo, J. W., Connelly, S., \& Dimeff, L. A. (1991). Reciprocal peer tutoring: A classroom strategy for promoting academic and social integration in undergraduate students. Journal of social behavior and personality, 6(2), 387-396.

Soller, A. (2001). Supporting Social Interaction in an Intelligent Collaborative Learning System. International Journal of Artificial Intelligence in Education, 12(1), 40-62.

Stahl, G., Koschmann, T., \& Suthers, D. (2006). Computer-supported collaborative learning: An historical perspective. In R. K. Sawyer (Ed.), Cambridge handbook of the learning sciences (pp. 409-426). Cambridge University Press.

Teasley, S., Fischer, F., Dillenbourg, P., Kapur, M., Chi, M., Weinberger, A., \& Stegmann, K. (2008). Cognitive Convergence in Collaborative Learning. In G. Kanselaar, V. Jonker, P. A. Kirschner, 
\& F. J. Prins, International Perspectives in the Learning Sciences: Cre8ing a learning world. Proceedings of the Eighth International Conference for the Learning Sciences - ICLS 2008 (pp. 360-367). Utrecht, The Netherlands: International Society of the Learning Sciences. Doi: $10.5555 / 1599936.1600039$

Tenenbaum, H. R., Winstone, N. E., Leman, P. J., \& Avery, R. E. (2020). How effective is peer interaction in facilitating learning? A meta-analysis. Journal of Educational Psychology, 112(7), 13031319. https://doi.org/10.1037/edu0000436

Thurston, A., Duran, D., Cunningham, E., Blanch, S., \& Topping, K. (2009). International on-line reciprocal peer tutoring to promote modern language development in primary schools. Computers \& Education, 53, 462-472. https://doi.org/10.1016/j.compedu.2009.03.005

Thurston, A., Roseth, C., Chiang, T., Burns, V., Topping, K. (2020). The influence of social relationships on outcomes in mathematics when using peer tutoring in elementary school. International Journal of Educational Research Open, 1. Doi: 10.1016/j.ijedro.2020.100004.

Topping, K. J. (2005). Trends in Peer Learning. Educational Psychology, 25(6), 631-645. https://doi.org/ $10.1080 / 01443410500345172$

Tsuei, M. (2011). Development of a peer-assisted learning strategy in computer-supported collaborative learning environments for elementary school students. British Journal of Educational Technology, 42(2), 214-232. https://doi.org/10.1111/j.1467-8535.2009.01006.x

Tsuei, M. (2012). Using synchronous peer tutoring system to promote elementary students' earning in mathematics. Computers \& Education, 58(4), 1171-1182. https://doi.org/10.1016/j.compedu.2011. 11.025

Tytler, R. (2000). A comparison of year 1 and year 6 students' conceptions of evaporation and condensation: dimensions of conceptual progression. International Journal of Science Education, 22(5), 447-467. https://doi.org/10.1080/095006900289723

van Laar, E., van Deursen, A. J., van Dijk, J. A., \& de Haan, J. (2017). The relation between 21st-century skills and digital skills: A systematic literature review. Computers in Human Behavior(72), 577-588. DOI https://dx.doi.org/10.1016/j.chb.2017.03.010

Veerman, A. L., \& Veldhuis-Diermanse, E. A. (2001). Collaborative learning through computer-mediated communication in academic education. Proceedings European Perspectives on Computer Supported Collaborative Learning : Euro-CSCL (pp. 625-632). Maastricht: Maastricht McLuhan Institute. Retrieved from http://www.ll.unimaas.nl/euro-cscl/Papers/166.doc

Voogt, J., \& Roblin, N. P. (2012). A comparative analysis of international frameworks for 21st century competences: Implications for national curriculum policies. Journal of Curriculum Studies, 44(3), 299-321. Doi: /10.1080/00220272.2012.668938

Walker, E., Rummel, N., \& Koedinger, K. R. (2009). Integrating Collaboration and Intelligent Data in The Evaluation of a Reciprocal Peer Tutoring Environment. Research and Practice in Technology Enhanced Learning, 4(3), 221-251.

Walker, E., Rummel, N., \& Koedinger, K. R. (2011). Designing automated adaptive support to improve student helping behaviors in a peer tutoring activity. International Journal of Computer-Supported Collaborative Learning, 6(2), 279-306.

Wang, F., \& Hannafin , M. J. (2005). Design-based research and technology-enhanced learning environments. Educational Technology Research and Development volume, 53(4), 5-23. Doi: /10.1007/ BF02504682

Weber, R. P. (1990). BASIC CONTENT ANALYSIS. Sage Publications, Inc..

Yang, E., Chang, B., Cheng, H., \& Chan, T.-W. (2016). Improving Pupils' Mathematical Communication Abilities through Computer-Supported Reciprocal Peer Tutoring. Educational Technology \& Society, 19(3), 157-169.

Publisher's note Springer Nature remains neutral with regard to jurisdictional claims in published maps and institutional affiliations. 


\section{Authors and Affiliations}

Riitta Maarit Oikarinen ${ }^{1}$ (D) Juho Kaleva Oikarinen ${ }^{2} \cdot$ Sari Havu-Nuutinen $^{1}$. Susanna Pöntinen ${ }^{1}$

Juho Kaleva Oikarinen

juho.oikarinen@opedu.kuopio.fi

Sari Havu-Nuutinen

sari.havu-nuutinen@uef.fi

Susanna Pöntinen

susanna.pontinen@uef.fi

1 Philosophical Faculty, University of Eastern Finland, Kuopio, Finland

2 Upper secondary school of Kuopio Lyseo, Kuopio, Finland 